\title{
Identification of Small and Non-Small Cell Lung Cancer Markers in Peripheral Blood Using Cytokinesis-Blocked Micronucleus and Spectral Karyotyping Assays
}

\author{
Randa A. El-Zein ${ }^{a, c}$ Shereen Abdel-Rahman ${ }^{d}$ Kyle J. Santee ${ }^{d}$ Robert Yu ${ }^{b}$ \\ Sanjay Shete ${ }^{b, c}$ \\ a Department of Radiology, Houston Methodist Research Institute, and Departments of ${ }^{\mathrm{b}}$ Biostatistics and

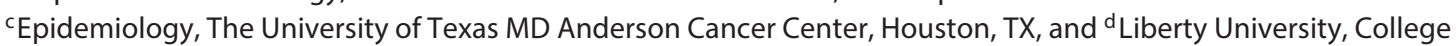 \\ of Osteopathic Medicine, Lynchburg, VA, USA
}

\section{Keywords}

Cytokinesis-blocked micronucleus assay · Genetic instability · Non-small cell lung cancer · Small cell lung cancer

\begin{abstract}
Small cell lung cancer (SCLC) is a highly aggressive form of lung cancer. There is an urgent need to develop tools to identify individuals at high risk of developing SCLC. We have previously reported that the cytokinesis-blocked micronucleus (CBMN) assay is a strong predictor of non-small cell lung cancer (NSCLC). Here, we investigate the sensitivity of the CBMN endpoints as predictors of SCLC risk. We conducted the CBMN assay on SCLC patients $(n=216)$, NSCLC patients ( $n=173)$, and healthy controls $(n=204)$. Per sample, 1,000 binucleated cells (BN) were scored, and 3 endpoints, micronuclei (BN-MN), nucleoplasmic bridges (BN-NPB), and nuclear buds (BN-BUD), were recorded. Spectral karyotyping was also conducted on SCLC patients $(n=116)$ and NSCLC patients ( $n=137$ ) to identify genomic regions unique to each disease. Significantly higher levels of CBMN endpoints were observed in both cancer groups compared to controls. BN-NPBs were significantly higher among SCLC patients
\end{abstract}

\section{KARGER}

(C) 2017 S. Karger AG, Basel

E-Mail karger@karger.com

www.karger.com/cgr compared to NSCLC patients ( $p<0.001)$. Chromosomes 5 and 17 were associated with BN-MN, and chromosomes 5, 18,20 , and 22 were associated with BN-NPBs in SCLC patients. Given the high frequency of chromosome aberrations observed in SCLC, events such as reinsertion of the micronucleus and chromothripsis may be potential mechanisms for the genetic instability in these patients.

(C) 2017 S. Karger AG, Basel

Approximately $85 \%$ of all lung cancers are non-small cell lung cancer (NSCLC) while the remaining 15\% are of the small cell lung cancer (SCLC) histological subtype. When independently considered from NSCLC, SCLC is the fifth leading cause of cancer mortality in the United States [Argiris and Murren, 2001]. SCLC may be differentiated from NSCLC by its increased doubling time, exponential growth fraction, and the development of metastases at an earlier time. SCLC is one of the most aggressive and lethal human cancers. Most SCLC cases are diagnosed after metastatic spread of the disease, and only $5 \%$ of patients survive beyond 5 years after diagnosis [Worden and Kalemkerian, 2000; Cooper and Spiro, 2006] as compared to $18 \%$ for NSCLC [Ferlay et al., 2010].

Randa A. El-Zein, MD, PhD Department of Radiology Houston Methodist Research Institute 6670 Bertner Ave, Houston, TX 77030 (USA) E-Mail rel-zein2@ houstonmethodist.org 
Similar to NSCLC, smoking is a major risk factor for development of SCLC with more than $90 \%$ of patients with SCLC being elderly, current or former, heavy smokers, and the risk rises with increasing duration and intensity of smoking [Devesa et al., 2005]. In industrialized countries, the annual incidence of SCLC has decreased over the past 30 years, partly attributed to changes in smoking patterns and diagnostic criteria. Staging of SCLC was originally based on the extent of the disease into "limited disease" or "extensive disease." Median survival without treatment has been reported as 2-4 months [Greene, 2006; Rami-Porta et al., 2007]. Further, the major reproducible prognostic factor remains disease extent.

An early event in carcinogenesis is the induction of genomic instability that enables an initiated cell to evolve into a cancer cell by achieving a greater proliferative capacity [Fenech, 2002b]. It has been reported that TP53 mutations are present in approximately $75-90 \%$ of SCLC, resulting in a highly complex disease at the molecular level [D’Amico et al., 1992; Miller et al., 1992]. Moreover, studies have found that SCLC is associated with a high incidence of chromosomal changes in the form of deletions in specific chromosomes such as $3 \mathrm{p}, 4 \mathrm{q}, 5 \mathrm{q}, 10 \mathrm{q}$, 13q, and 17p [Petersen et al., 1997], as well as 9p and 3q [Zhao et al., 2005].

Cytogenetic biomarkers have been strongly validated as markers of cancer risk in both cohort and nested casecontrol studies [Tucker and Preston, 1996; Liou et al., 1999; Bonassi et al., 2000, 2004; Smerhovsky et al., 2001], reflecting the outcome of both the genotoxic effects of carcinogens and individual cancer susceptibility. Assuming that the mechanisms for the induction of chromosomal damage are similar in different tissues, the extent of chromosomal damage evaluated in peripheral blood lymphocytes (PBLs) and other surrogate tissues likely reflects the level of damage in cancer-prone tissues and in turn cancer risk [Norppa et al., 2006]. Studies of paired lung tumors and PBLs from the same patients have demonstrated that genomic instability in the tumors corresponded well to PBL chromosomal changes and suggested that chromosomes commonly altered in both tumors and PBLs represent early events necessary for tumor initiation. Whereas, those chromosomes commonly rearranged in tumors only represent later events in the sequence of cancer development and progression [Pathak et al., 1991; Dave et al., 1995; Gjayee et al., 1997]. Further support for the value of PBL chromosomal changes as markers of early detection is provided through studies of adenomatous polyp patients and their asymptomatic first-degree relatives [Dave et al., 1993].

Biological Markers for Lung Cancer Subtypes
The cytokinesis-blocked micronucleus (CBMN) assay in human lymphocytes is one of the most commonly used cytogenetic methods for measuring DNA damage [Fenech, 2000, 2007]. The CBMN assay is a multi-endpoint assay that assesses DNA damage endpoints (in the form of binucleated cells with micronuclei [BN-MN], nucleoplasmic bridges [BN-NPBs], and nuclear buds [BNBUDs]) as well as other cellular events (such as necrosis, apoptosis, and cell proliferation) simultaneously. BNMN are identified as chromosome fragments or whole chromosomes that fail to engage with the mitotic spindle and therefore lag behind when the cell divides. BN-NPBs originate from asymmetrical chromosome rearrangements and/or telomere end fusions [Umegaki and Fenech, 2000; Stewenius et al., 2005]. BN-BUDs represent a mechanism by which cells remove amplified DNA and are therefore considered a marker of possible gene amplification through a breakage-fusion-bridge cycle [Fenech, 2002a]. We have previously reported that the CBMN DNA damage endpoints are strong predictors of NSCLC susceptibility [El-Zein et al., 2006, 2008, 2014; McHugh et al., 2013] with a positive predictive value of $91 \%$ among smokers.

Although the more recent National Lung Screening Trial signaled the use of low-dose computed tomography imaging for early detection of overall lung cancers, the finding for patients with SCLC was contradictory as $86 \%$ of the 125 patients with SCLC identified through early detection programs had advanced disease at diagnosis [Byers and Rudin, 2015]. To address the lack of current methods with proven efficacy for the early detection of SCLC, we investigated the sensitivity of the CBMN endpoints as a predictor of SCLC risk. Furthermore, we broadened our investigation by using molecular cytogenetic techniques to map the regions in the genome associated with SCLC.

\section{Materials and Methods}

\section{Study Population}

SCLC cases, NSCLC cases, and cancer-free controls were recruited from an on-going NIH-funded lung cancer case-control study at The University of Texas MD Anderson Cancer Center. SCLC cases $(n=216)$ were consecutive patients with newly diagnosed, previously untreated, histologically confirmed SCLC with no age, gender, or ethnicity restrictions. NSCLC cases $(n=196)$ were matched to the SCLC cases on age ( \pm 5 years) and gender. All lung cancer patients were treated in the Thoracic Surgery, Thoracic Oncology, or Pulmonary Units at the University of Texas MD Anderson Cancer Center. Healthy controls $(n=229)$ were recruited from the Kelsey-Seybold Clinic, a multi-specialty practice in

Cytogenet Genome Res 2017;152:122-131

DOI: $10.1159 / 000479809$ 
the Houston metropolitan area. Medical history, family history of cancer, smoking habits, and occupational history were obtained through an interviewer-administered risk-factor questionnaire and by the review of an institutional electronic patient history database. For all participants, former smokers were individuals who had smoked at least 100 cigarettes in their lifetime but quit at least 12 months prior to lung cancer diagnosis (for cases) or prior to the interview (for controls). Data on smoking history included smoking duration, number of cigarettes smoked per day and pack years smoked (e.g., computed by multiplying smoking duration [in years] by the number of cigarettes smoked per day and then dividing by 20). Upon informed consent, a $10-\mathrm{mL}$ blood sample was drawn into coded heparinized tubes from all study participants for the assays.

\section{Cytokinesis-Blocked Micronucleus Assay}

Cytogenetic cultures for the CBMN assay were prepared using peripheral blood from all cases and controls following the method described by Fenech and Morley [1985] and the International Collaborative Project on Micronucleus Frequency in Human Populations [Fenech et al., 2003]. Lymphocyte cultures were prepared in duplicate for each study participant. Each culture contained $2.0 \times$ $10^{6}$ cells in 5 mL RPMI 1640 medium supplemented with $100 \mathrm{U} /$ $\mathrm{mL}$ penicillin, $100 \mu \mathrm{g} / \mathrm{mL}$ streptomycin, $10 \%$ fetal bovine serum, 2 mM L-glutamine (Gibco-Invitrogen, Carlsbad, CA), and 1\% phytohemagglutinin (Remel, Lenexa, KS) and was incubated at $37^{\circ} \mathrm{C}$. At $44 \mathrm{~h}$ after initiation, cytochalasin B (final concentration $4 \mu \mathrm{g}$ / $\mathrm{mL}$ ) was applied to block the cells in cytokinesis (Sigma, St. Louis, MO). Following incubation, the cells were fixed in 3:1 methanol:glacial acetic acid, dropped onto clean microscopic slides, airdried, and stained with Giemsa stain. Using the scoring criteria delineated by the HUMN Project [Fenech et al., 2003], 1,000 binucleated cells per sample were scored blindly to the case/control status using a Nikon E-400 light optical microscope. Binucleated cells were then evaluated for the frequency of micronuclei (BN$\mathrm{MN}$ ), nucleoplasmic bridges (BN-NPB), and nuclear buds (BNBUD).

\section{Spectral Karyotyping Analysis}

In order to identify the specific chromosomes involved in $\mathrm{BN}$ $\mathrm{MN}, \mathrm{BN}-\mathrm{NPB}$, and BN-BUD formation among SCLC and NSCLC, we performed spectral karyotyping (SKY) analysis on study participants for whom sufficient culture material was available for further analyses (SCLC, $n=116$ and NSCLC, $n=137$ ). For purposes of probe conservation, cultured cells from cases and controls were dropped onto a small $2 \times 2 \mathrm{~cm}$ localized area on the slides. Human SKY kit (Applied Spectral Imaging [ASI], Israel) was used, following the manufacturer's recommendations. Briefly, slides were pretreated with pepsin, to reduce the background in the fluorescence, followed by 2 washes with solution $\mathrm{A}\left(1 \times \mathrm{PBS} / \mathrm{MgCl}_{2}\right)$ and a second wash with solution $\mathrm{B}\left(1 \times \mathrm{PBS} / \mathrm{MgCl}_{2}\right.$ and $1 \%$ formaldehyde $)$ for 10 min each. Slides were then denatured in $70 \%$ formamide at $75^{\circ} \mathrm{C}$ for 2-3 min. In parallel, a human SKY probe was denatured at $80^{\circ} \mathrm{C}$ for $7 \mathrm{~min}$, and incubated at $37^{\circ} \mathrm{C}$ for $60 \mathrm{~min}$. Subsequently, $5 \mu \mathrm{L}$ of the denatured probe was added to a predetermined area on the slides that contained cells with BN-MN and BN-NPBs. The hybridization was carried out for $48 \mathrm{~h}$ at $37^{\circ} \mathrm{C}$ in a humidity chamber, and the excess of the probe was removed. The hybridized slides were stained using anti-digoxin and Cy5-streptavidin and Cy5.5 antibody. The slides were then counterstained with DAPI in an antifade solution (ASI). Twenty-five images per sample were captured and analyzed using the SKY paint probes multispecies software (ASI). This software allows the identification of the chromosomes predominantly involved in the formation of the chromosome alteration events based on pixel color.

\section{Statistical Analysis}

SAS 9.3 (Windows version 6.1.7601) was used to perform descriptive statistics, $t$ tests, and logistic regression analyses. Unpaired $t$ tests were used to compare differences of age, smoking status, pack years smoked, years smoked, number of cigarettes, and the CBMN endpoints (BN-MN, BN-NPB, BN-BUDs) between the 3 study groups (SCLC, NSCLC, and controls) yielding 2 testing $p$ values based on equality of variance. The method pooled $t$ test was used for equal variance comparison and the Satterthwaite $t$ test was used for unequal variance comparison. The method Folded $F$ test was performed to examine the equality of variance. An unequal variance $t$ test was based upon a significant $p$ value of the $F$ test. A Kruskal-Wallis test of difference was also performed.

Exact logistic univariate regression, adjusted by age, sex, smoking status, pack years, year smoked, and/or number of cigarettes was performed in the SCLC cases, NSCLC cases, and controls on CBMN endpoints (BN-MN, BN-NPB, BN-BUDS). Based on these findings, a set of significant covariate(s) and variables were then selected to run the multivariate logistic regression using stepwise, forward, backward, and score methods to confirm the significance of variable effects. To control for multiple testing bias, a false discovery rate estimation of combined $87 p$ values from all the tests above was performed. The procedure of MUTTEST in SAS and the fdrtool package in R software (version 3.0.3) were both used for the estimation. Both identified a cutoff $p$ value of 0.0247 for the family-wise significance.

\section{Results}

The demographic characteristics of the SCLC cases, NSCLC cases, and controls are summarized in Table 1. All the SCLC cases $(n=216)$ were non-Hispanic Whites versus 88 and $89 \%$ of the NSCLC cases and the controls, respectively. Therefore, all the analyses were limited to non-Hispanic Whites, resulting in sample sizes of 173 for the NSCLC cases and 204 for controls. The SCLC cases, NSCLC cases, and controls did not differ significantly in terms of gender with $45.8,47.4$, and $51.5 \%$ of males, respectively $(p>0.05)$. All 3 groups smoked approximately the same number of cigarettes per day (mean number of cigarettes per day \pm SE for SCLC cases: $25.9 \pm 14.2$, for NSCLC: $25.9 \pm 12.9$, and for controls: $24.8 \pm 13.0 ; p>$ $0.05)$. The duration of smoking was significantly less among the SCLC cases (mean \pm SE of $35.8 \pm 9.8$ years) as compared to $39.9 \pm 11.5$ years among the NSCLC cases $(p<0.0003)$ and $37.5 \pm 9.8$ years for the controls $(p<0.08)$.

Overall, both SCLC cases and NSCLC cases exhibited significantly higher values of all DNA damage endpoints 
Table 1. Demographic characteristics of the SCLC cases, NSCLC cases, and controls

\begin{tabular}{|c|c|c|c|c|c|c|}
\hline \multirow[t]{2}{*}{ Variables } & \multirow[t]{2}{*}{ SCLC } & \multirow[t]{2}{*}{ NSCLC } & \multirow[t]{2}{*}{ Controls } & \multicolumn{3}{|c|}{$t$ test $p$ values } \\
\hline & & & & $\begin{array}{l}\text { SCLC vs. } \\
\text { controls }\end{array}$ & $\begin{array}{l}\text { NSCLC vs. } \\
\text { controls }\end{array}$ & $\begin{array}{l}\text { SCLC vs. } \\
\text { NSCLC }\end{array}$ \\
\hline Age, years ${ }^{\mathrm{a}}$ & $63.8 \pm 7.7$ & $63.5 \pm 8.6$ & $63.8 \pm 7.1$ & 0.9857 & $0.6836^{\mathrm{b}}$ & 0.6971 \\
\hline Median age & 65 & 63 & 64 & & & \\
\hline \multicolumn{4}{|l|}{ Gender } & 0.2490 & 0.4321 & 0.7591 \\
\hline Male, $n(\%)$ & $99(45.8)$ & $82(47.4)$ & $105(51.5)$ & & & \\
\hline Female, $n(\%)$ & $117(54.2)$ & $91(52.6)$ & $99(48.5)$ & & & \\
\hline \multicolumn{4}{|l|}{ Smoking status ${ }^{c}$} & 0.9775 & 0.8297 & 0.8467 \\
\hline Current, $n(\%)$ & $140(65)$ & $114(66)$ & $133(66)$ & & & \\
\hline Former, $n(\%)$ & $75(35)$ & $58(34)$ & $69(34)$ & & & \\
\hline \multirow{2}{*}{$\begin{array}{l}\text { Pack years }^{\mathrm{a}} \\
\text { Median number }\end{array}$} & $46.9 \pm 30.0$ & $50.7 \pm 27.7$ & $46.8 \pm 28.0$ & 0.9780 & 0.1765 & 0.1973 \\
\hline & 40 & 45 & 40 & & & \\
\hline \multirow{2}{*}{$\begin{array}{l}\text { Smoking duration, years } \\
\text { Median number }\end{array}$} & $35.8 \pm 9.8$ & $39.9 \pm 11.5$ & $37.5 \pm 9.8$ & 0.0839 & $0.0309^{b}$ & $0.0003^{b}$ \\
\hline & 36 & 40 & 39 & & & \\
\hline \multirow{2}{*}{$\begin{array}{l}\text { Cigarettes per day, } n^{\mathrm{a}} \\
\text { Median number }\end{array}$} & $25.9 \pm 14.2$ & $25.9 \pm 12.9$ & $24.8 \pm 13.0$ & 0.3948 & 0.4314 & 0.9552 \\
\hline & 20 & 20 & 20 & & & \\
\hline
\end{tabular}

${ }^{a}$ Values for SCLC, NSCLC, and controls are given as mean \pm SE. ${ }^{b}$ Unequal variance $t$ test. ${ }^{c}$ Smoking status was measured at 3 levels, "current," "former," and "never." Due to the extremely small number of "never" ( 2 in the control group and 1 in both the NSCLC and SCLC groups), this category was dropped off the data set in the analysis using smoking status.

Significant $p$ values are in bold.

than the non-cancer controls $(p<0.0001)$. Data on CBMN endpoints, frequencies by age, gender, smoke years, and smoking status are summarized in Table 2 and showed no significant differences among the comparison groups.

The mean number of BN-MN in both the SCLC cases and NSCLC cases was significantly different when compared to controls (mean $\pm \mathrm{SE}=3.74 \pm 0.98$ and $3.79 \pm 0.96$ vs. $1.43 \pm 0.68$ respectively, $p=0.0001$ ). However, there were no significant differences between the SCLC cases and NSCLC cases $(p=0.57)$. Figure $1 \mathrm{~A}$ shows that approximately $95 \%$ of SCLC cases had $>2 \mathrm{MN} / 1,000$ binucleated cells (range 1-6 BN-MN/1,000 cells), compared with $98 \%$ of NSCLC cases (range 1-6 BN-MN/1,000 cells) and $2.6 \%$ of control participants (range $0-4 \mathrm{BN}-\mathrm{MN} / 1,000$ cells), and that $97.5 \%$ of the control participants had 0 or $1 \mathrm{MN}$, compared with only $5 \%$ of the SCLC cases and $2 \%$ of the NSCLC cases, respectively $(p<0.001)$.

The mean number of BN-NPB was significantly different between the 3 comparison groups, where the mean \pm SE for SCLC cases was $4.39 \pm 1.19$ as compared to $4.05 \pm$ 0.95 in NSCLC cases $(p=0.0014)$ and $0.70 \pm 0.62$ in con-

Biological Markers for Lung Cancer Subtypes trols $(p<0.001)$. Figure 1B demonstrates that approximately $94 \%$ of SCLC cases had $>2$ NPBs/1,000 binucleated cells (range 1-7 NPBs/1,000 cells), similar to the NSCLC cases (range 1-6 NPBs/1,000 cells) and $1 \%$ of control participants (range $0-3 \mathrm{NPBs} / 1,000$ cells), and that $93 \%$ of the control participants had 0 or $1 \mathrm{NPB}$, compared with only $1.8 \%$ of the SCLC cases and $0 \%$ of the NSCLC cases, respectively $(p<0.001)$.

Overall, due to the rarity of the events, the average number of BN-BUDs was not different among the 3 comparison groups with a range of 0-1 BN-BUDs in SCLC cases and controls as compared to $0-2$ in NSCLC cases. No substantial differences were detected when the frequencies of BN-MN, BN-NPBs, and BN-BUDs were stratified by gender, age, number of years smoked, number of cigarettes per day, or disease stage.

When the BN-MN data were analyzed as a continuous variable, using multivariate logistic regression, there was a 36.11-fold increase in SCLC risk (95\% CI, 17.20-75.80) and a 172.95-fold increase in NSCLC risk (95\% CI, 55.15542.33) for each 1 -unit increase in micronucleus frequen-

Cytogenet Genome Res 2017;152:122-131 DOI: $10.1159 / 000479809$ 
cy. Similarly, when BN-NPBs were analyzed as a continuous variable, there was a 25.26 -fold increase in SCLC risk (95\% CI, 11.12-57.35) and a 70.5-fold increase in NSCLC risk (95\% CI, 17.70-280.79) for each 1-unit increase in BN-NPBs. Comparing the BN-NPBs among SCLC versus NSCLC revealed a $32 \%$ increase in risk for each 1-unit increase in BN-NPBs (Table 3).

A total of 2,900 cells were scored using SKY imaging for SCLC and 3,425 cells for NSCLC to identify a chromosome-specific involvement in the formation of $\mathrm{BN}$ $\mathrm{MN}, \mathrm{BN}-\mathrm{NPBs}$, and BN-BUDs in the 2 lung cancer groups. Fewer chromosomes were involved in $\mathrm{BN}-\mathrm{MN}$ formation in the SCLC (chromosomes 1, 3, 5, 8, 13, 17, 20-22, and X) as compared to NSCLC (chromosomes 1, $3,4,6,8,10,11,13-16,18,21,22$, and $\mathrm{X}$ ) group. BN-MN involving chromosomes $1,3,8,21,22$, and $\mathrm{X}$ were seen in both SCLC and NSCLC cases; however, the frequency of $\mathrm{BN}-\mathrm{MN}$ formation was significantly higher in the SCLC cases as compared to the NSCLC cases. Figure 2A shows the distribution of each of these chromosomes by disease status. The percentage of observed events was 5.4, 5.7, 3.6, 1.9 , and $1.9 \%$ for SCLC versus 2.2, 2.6, 1.9, 1.0, and 1.1\% for NSCLC for chromosomes 1, 3, 8, 21, and 22, respectively. The percentage of observed events for the X chromosome was slightly higher among the NSCLC cases. $\mathrm{BN}-\mathrm{MN}$ involving chromosomes 5 and 17 were exclusively seen among the SCLC cases, and BN-MN involving chromosomes $4,6,10,11,13,14,15,16$, and 18 were exclusively seen among the NSCLC cases. We further found that cells from all SCLC cases harbored BM-MN originating from chromosomes $1,3,5$, and 8 .

More chromosomes were involved in BN-NPB formation in the SCLC cases compared to NSCLC cases. Chromosomes 2, 4-6, 9, 13, 14, 17-20, 22, and X were detected in BN-NPB formation among SCLC cases, while chromosomes 1-4, 9, 13,14, 17, 19, and $\mathrm{X}$ were involved in $\mathrm{BN}$ NPB formation among the NSCLC cases. The frequencies of BN-NPB involving chromosomes 2, 4, 9, 13, 14, 17, 19, and X observed in both SCLC and NSCLC cases were not significantly different. Figure $2 \mathrm{~B}$ shows the distribution frequency of each of these chromosomes by disease status. BN-NPB involving chromosomes 5, 18, 20, and 22 were exclusively seen among the SCLC cases. BN-NPB involving chromosomes 1 and 3 were exclusively seen among the NSCLC cases.

Gene amplification as reflected by BN-BUD formation involved only 2 chromosomes ( 2 and 8 ) among the SCLC cases. Chromosome 2 was involved in BN-BUD formation among both groups but with a significantly higher frequency (5.5\% of cells) among the SCLC cases
Table 2. Overall frequencies of BN-MN, BN-NPBs, and BN-BUDs per 1,000 binucleated cells in SCLC cases, NSCLC cases, and controls

\begin{tabular}{|c|c|c|c|c|c|c|}
\hline \multirow{4}{*}{ BN-MN } & \multicolumn{2}{|l|}{ SCLC cases } & \multicolumn{2}{|c|}{ NSCLC cases } & \multicolumn{2}{|l|}{ Controls } \\
\hline & \multicolumn{2}{|c|}{ mean \pm SE $n$} & \multicolumn{2}{|c|}{ mean \pm SE $n$} & \multirow[t]{2}{*}{ mean $\pm \mathrm{SE}$} & \multirow[t]{2}{*}{$n$} \\
\hline & & & & & & \\
\hline & \multicolumn{6}{|c|}{ Gender } \\
\hline Male & $3.69 \pm 1.02$ & 99 & $3.76 \pm 1.01$ & 82 & $1.50 \pm 0.64$ & 105 \\
\hline Female & $3.78 \pm 0.96$ & 117 & $3.82 \pm 0.91$ & 91 & $1.34 \pm 0.72$ & 99 \\
\hline \multicolumn{7}{|l|}{ Age } \\
\hline$\leq$ Median & $3.66 \pm 1.05$ & 119 & $3.97 \pm 1.01$ & 88 & $1.36 \pm 0.73$ & 107 \\
\hline$>$ Median & $3.84 \pm 0.90$ & 97 & $3.68 \pm 0.90$ & 85 & $1.51 \pm 0.61$ & 97 \\
\hline \multicolumn{7}{|c|}{ Smoking status } \\
\hline Current & $3.75 \pm 0.99$ & 140 & $3.89 \pm 0.99$ & 114 & $1.44 \pm 0.69$ & 133 \\
\hline Former & $3.71 \pm 0.98$ & 76 & $3.62 \pm 0.88$ & 58 & $1.41 \pm 0.67$ & 71 \\
\hline \multicolumn{7}{|l|}{ Years smoked } \\
\hline$\leq$ Median & $3.73 \pm 0.94$ & 110 & $3.81 \pm 1.01$ & 104 & $1.40 \pm 0.71$ & 106 \\
\hline$>$ Median & $3.75 \pm 1.03$ & 106 & $3.77 \pm 0.89$ & 69 & $1.46 \pm 0.64$ & 98 \\
\hline Overall & $3.74 \pm 0.98$ & 216 & $3.79 \pm 0.96$ & 173 & $1.43 \pm 0.68$ & 204 \\
\hline \multicolumn{7}{|l|}{ BN-NPBs } \\
\hline \multicolumn{7}{|l|}{ Gender } \\
\hline Male & $4.26 \pm 1.22$ & 99 & $4.01 \pm 0.97$ & 82 & $0.72 \pm 0.66$ & 105 \\
\hline Female & $4.50 \pm 1.16$ & 117 & $4.08 \pm 0.92$ & 91 & $0.67 \pm 0.59$ & 99 \\
\hline \multicolumn{7}{|l|}{ Age } \\
\hline$\leq$ Median & $4.34 \pm 1.14$ & 119 & $4.01 \pm 0.95$ & 88 & $0.71 \pm 0.66$ & 107 \\
\hline$>$ Median & $4.46 \pm 1.24$ & 97 & $4.08 \pm 0.94$ & 85 & $0.68 \pm 0.59$ & 97 \\
\hline \multicolumn{7}{|l|}{ Smoking status } \\
\hline Current & $4.41 \pm 1.23$ & 140 & $3.94 \pm 0.94$ & 114 & $0.70 \pm 0.59$ & 133 \\
\hline Former & $4.37 \pm 1.12$ & 76 & $4.24 \pm 0.92$ & 58 & $0.69 \pm 0.69$ & 71 \\
\hline \multicolumn{7}{|l|}{ Years smoked } \\
\hline$\leq$ Median & $4.55 \pm 1.19$ & 110 & $4.06 \pm 0.91$ & 104 & $0.72 \pm 0.60$ & 106 \\
\hline$>$ Median & $4.24 \pm 1.17$ & 106 & $4.03 \pm 1.00$ & 69 & $0.67 \pm 0.65$ & 98 \\
\hline Overall & $4.39 \pm 1.19$ & 216 & $4.05 \pm 0.95$ & 173 & $0.70 \pm 0.62$ & 204 \\
\hline \multicolumn{7}{|l|}{ BN-BUDs } \\
\hline \multicolumn{7}{|l|}{ Gender } \\
\hline Male & $0.43 \pm 0.50$ & 99 & $0.45 \pm 0.57$ & 82 & $0.47 \pm 0.50$ & 105 \\
\hline Female & $0.45 \pm 0.50$ & 117 & $0.41 \pm 0.52$ & 91 & $0.53 \pm 0.50$ & 99 \\
\hline \multicolumn{7}{|l|}{ Age } \\
\hline$\leq$ Median & $0.44 \pm 0.50$ & 119 & $0.45 \pm 0.52$ & 88 & $0.44 \pm 0.50$ & 107 \\
\hline$>$ Median & $0.45 \pm 0.50$ & 97 & $0.40 \pm 0.56$ & 85 & $0.56 \pm 0.50$ & 97 \\
\hline \multicolumn{7}{|c|}{ Smoking status } \\
\hline Current & $0.42 \pm 0.50$ & 140 & $0.39 \pm 0.54$ & 114 & $0.51 \pm 0.50$ & 133 \\
\hline Former & $0.49 \pm 0.50$ & 76 & $0.50 \pm 0.54$ & 58 & $0.46 \pm 0.50$ & 71 \\
\hline \multicolumn{7}{|l|}{ Years smoked } \\
\hline$\leq$ Median & $0.48 \pm 0.50$ & 110 & $0.48 \pm 0.56$ & 104 & $0.48 \pm 0.50$ & 106 \\
\hline$>$ Median & $0.41 \pm 0.49$ & 106 & $0.35 \pm 0.51$ & 69 & $0.51 \pm 0.50$ & 98 \\
\hline Overall & $0.44 \pm 0.50$ & 216 & $0.43 \pm 0.54$ & 173 & $0.50 \pm 0.50$ & 204 \\
\hline
\end{tabular}

versus $0.8 \%$ among the NSCLC cases. Chromosome 8 was exclusively involved in SCLC cases, while chromosomes $1,4,9-11,13,15,17,20$, and 21 were only involved in the NSCLC cases. Figure 2C shows the distribution frequency of each of these chromosomes by disease status.
El-Zein/Abdel-Rahman/Santee/Yu/Shete 
Table 3. Risk estimates of SCLC and NSCLC for CBMN endpoints

\begin{tabular}{|c|c|c|c|c|c|c|}
\hline \multirow[t]{2}{*}{ Variable } & \multicolumn{2}{|l|}{ SCLC vs. controls } & \multicolumn{2}{|l|}{ NSCLC vs. controls } & \multicolumn{2}{|l|}{ SCLC vs. NSCLC } \\
\hline & OR $(95 \% \mathrm{CI})$ & $p$ value & OR (95\% CI) & $p$ value & OR (95\% CI) & $p$ value \\
\hline BN-MN & $36.11(17.20-75.80)$ & $<0.0001$ & $172.95(55.15-542.33)$ & $<0.0001$ & $0.94(0.76-1.16)$ & 0.5554 \\
\hline $\mathrm{BN}-\mathrm{NPBs}$ & $25.26(11.12-57.35)$ & $<0.0001$ & $70.50(17.70-280.79)$ & $<0.0001$ & $1.32(1.09-1.59)$ & 0.0052 \\
\hline BN-BUDs & $0.82(0.56-1.20)$ & 0.3051 & $0.81(0.54-1.20)$ & 0.2903 & $1.00(0.68-1.49)$ & 0.9938 \\
\hline
\end{tabular}

Bolded $p$ values are considered significant according to the cutoff $p$ value for family-wise significance from false discovery rate estimation 0.0247 .

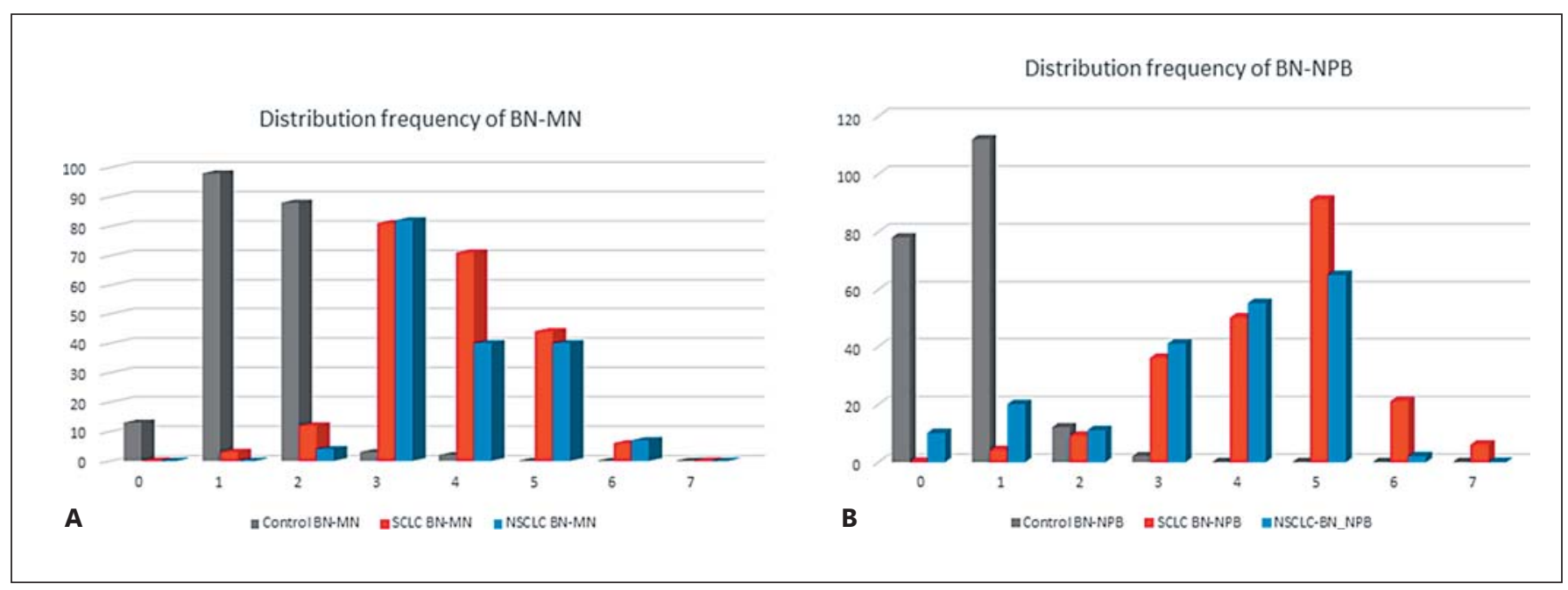

Fig. 1. Frequency distribution of $\mathrm{CBMN}$ endpoints among the study groups. A BN-MN distribution among SCLC versus NSCLC and controls. B BN-NPB distribution among SCLC versus NSCLC and controls.

\section{Discussion}

Chromosomal aberrations in the form of aneuploidy, numerical alterations as well as structural alterations are hallmarks of cancer [Masuda and Takahashi, 2002; Bonassi et al., 2011]. It has been shown that cancer cells accumulate a series of genetic changes, some of which can be identified by chromosomal analysis of PBLs [Dave et al., 1993]. In our study, we demonstrate that although both SCLC and NSCLC cases had significantly higher levels of genetic instability (BN-MN, BN-NPB, and BNBUDs) as compared to healthy cancer-free controls, only the levels of the BN-NPBs were significantly higher among the SCLC cases as compared to the NSCLC cases $(p<0.001)$. While we have previously reported that the multi-endpoint CBMN assay is a sensitive predictor of lung cancer risk [McHugh et al., 2013], to our knowledge, this is the first study to compare the level of genetic insta-

Biological Markers for Lung Cancer Subtypes bility between SCLC and NSCLC cases using this multiendpoint approach.

Comparison of specific chromosome damage within the 2 lung cancer groups revealed repeated involvement of several chromosomes in the pathogenesis of both SCLC and NSCLC. It has been shown that the regions of recurrent genomic alteration frequently harbor genes crucial to the carcinogenic process [Zhao et al., 2005; Ding et al., 2008]. In BN-MN formation, which is reflective of chromosome loss or aneuploidy, chromosomes 1 , $3,8,21,22$, and X were involved in both SCLC and NSCLC, however, a significantly higher frequency of involvement was observed among the SCLC for chromosomes 1,3 , and 8 . Chromosomes 5 and 17 involvement in $\mathrm{BN}-\mathrm{MN}$ formation was exclusively associated with SCLC, while several chromosomes were exclusively associated with NSCLC. In BN-NPB formation, which is reflective of structural rearrangements, several chromo-

Cytogenet Genome Res 2017;152:122-131 127 


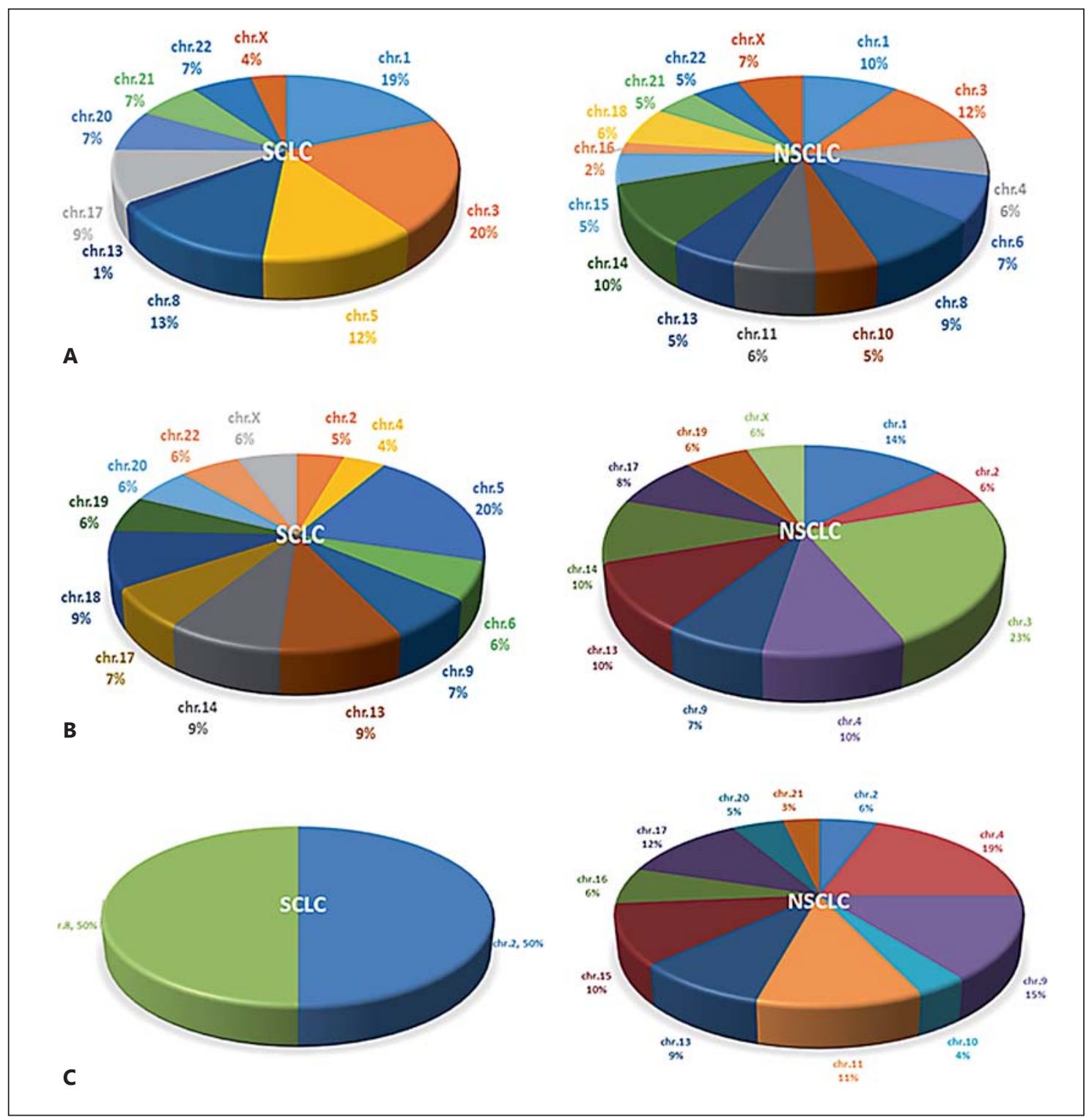

Fig. 2. Frequency of specific chromosome involvement by endpoint and disease status as detected by SKY analysis. A Chromosome involvement in BN-MN. B Chromosome involvement in BN-NPB. C Chromosome involvement in BN-BUD.

somes were associated with both SCLC and NSCLC with similar frequency. BN-NPB formation involving chromosomes 5, 18, 20, and 22 was exclusively associated with SCLC, and chromosomes 1 and 3 were associated with NSCLC. In terms of BN-BUD formation, which is reflective of gene amplifications, only chromosome 8 was exclusive to SCLC.

Several genetic and molecular alterations have been consistently reported in both NSCLC and SCLC, some of which were also noted in our study [Pei et al., 2001; Bal- sara and Testa, 2002; Masuda and Takahashi, 2002; Haga et al., 2005; Ma et al., 2006; van Meerbeeck et al., 2011]. Chromosome 1 involvement is a common event in lung cancer [Garnis et al., 2005], where it has been shown to harbor members of the WNT and NOTCH families that play a role in various cancers including NSCLC and SCLC [Hassan et al., 2014]. Chromosome 1 also carries a member of the MYC family of oncogenes, MYC lung carcinoma-derived homolog 1 (MYCL1), shown to be associated with SCLC [Wistuba et al., 2001]. In chromosome 2, an- 
other member of the MYC family, MYC neuroblastomaderived homolog (MYCN), is located. We observed amplifications involving chromosome 2 in both SCLC and NSCLC, however, an approximately 7-fold higher frequency of BN-BUDs was observed among the SCLC cases. In addition, amplification of chromosome 8, which harbors the third member of the MYC family, was observed and was exclusive to the SCLC group. Our findings support previous studies showing the 3 MYC family genes being frequently amplified in SCLCs [Wistuba et al., 2001; Kim et al., 2006; Voortman et al., 2010; Larsen and Minna, 2011; Sos et al., 2012].

Chromosome 3 has historically been characterized by chromosomal breakage near the centromere and other rearrangements in NSCLC [Pei et al., 2001; Balsara and Testa, 2002], while the deletion of the short arm of chromosome 3 has been seen in virtually all SCLC tumors [Franklin et al., 2010]. A number of candidate genes for lung cancer are located on chromosome 3 , including the oncogene PIK3CA [Qian and Massion, 2008; Schwartz et al., 2011] and the FHIT gene [van Meerbeeck et al., 2011] which is reportedly one of the most altered genes in cancer. The FHIT gene functions in DNA repair to help maintain genomic stability [Saldivar et al., 2010; Wali, 2010], thereby supporting our finding of a higher frequency of damage on chromosome 3 among SCLC and its involvement in virtually $100 \%$ of SCLC patients as compared to $47 \%$ of NSCLC patients.

In our present study, chromosome 8 was involved in BN-MN formation among both SCLC and NSCLC cases. A recent study identifying molecular markers that predict clinical outcomes among NSCLC patients reported that chromosome 8 harbored several significant alterations [Baykara et al., 2015]. The most frequently amplified genes on chromosome 8 were ZNF703 and PRDM14. ZNF703 is a zinc finger protein that when overexpressed increases genetic instability, contributes to tumor aggressiveness [Reynisdottir et al., 2013], and increases lung metastasis rates in breast cancer [Slorach et al., 2011]. Thus, these findings indicate that ZNF703 may function as an oncogene in different cancers and support our observation of higher genetic instability and BN-BUD formation (reflecting chromosome 8 amplifications) among SCLC cases. Similarly, PRDM14 has been identified as a susceptibility locus for cancer [Ruark et al., 2013], and its amplification and overexpression was shown to be associated with a more aggressive phenotype and reduced sensitivity to chemotherapy in breast cancer [Nishikawa et al., 2007]. To date, there are no reports addressing the association of PRDM14 with SCLC, however, given our ob-

Biological Markers for Lung Cancer Subtypes servation of BN-BUD formation involving chromosome 8 exclusively among SCLC patients, it is plausible that this gene plays a role in the aggressive phenotype and resistance to chemotherapy in SCLC patients.

Chromosome 17 harbors the tumor suppressor TP53, whose inactivation is implicated in various cancers. It has been reported that patients with SCLC have more frequently mutations in TP53 than do patients with NSCLC [Franklin et al., 2010] which supports our findings of higher frequency of chromosome 17 loss and rearrangements among SCLC cases than in NSCLC cases. Involvement of chromosome 22 is another interesting finding, as a recent study identified a potential oncogene, CRKL on 22q11, which may promote tumor cell proliferation, survival, and motility [Kim et al., 2010]. 22q12.2 has been recently identified as a new lung cancer susceptibility locus in a genome-wide association study of Han Chinese [Hu et al., 2011].

A recent study reviewed the fate and consequences of micronuclei and micronucleated cells and summarized the different potential fates as degradation of the micronucleus, elimination of the micronucleus from the cell, persistence in the cytoplasm, reinsertion into the main nucleus, elimination by apoptosis, and chromothripsis (chromosome shattering, within the confined space of the micronucleus, of one or a few chromosomes resulting in a large number of rearrangements) [Hintzsche et al., 2017]. The authors concluded that although the consequences of micronuclei remain unclear, the reinsertion and the persistence of the micronuclei lead to genetic imbalances in the daughter cells that contribute to both initiation and progression of the carcinogenic process. In addition, micronuclei formation is now recognized as a mechanism by which both chromothripsis and chromoanagenesis (complex genomic rearrangements occurring as a single catastrophic event) occur, and are major contributors to cancer initiation and development [Stephens et al., 2011; Crasta et al., 2012].

A recent study on genome-wide identification of genes with amplification and/or fusion in SCLC reported that several genes co-amplified with MYCL1 and MYC, and that these genes were likely to be rearranged and amplified as a result of an immense genomic rearrangement acquired in a single catastrophic event such as chromothripsis [Iwakawa et al., 2013]. The higher frequency of genetic alterations observed in our study among SCLC as compared to NSCLC may therefore be a consequence of any of the different micronuclei fates listed above. Detection of such genetic alterations in the blood of the patients is indicative of early carcinogenic events, and hence

Cytogenet Genome Res 2017;152:122-131 DOI: $10.1159 / 000479809$ 
they have the potential of being used as markers for detection of the early stage disease.

To date, SCLC continues to significantly lag behind NSCLC and other cancers in terms of molecular profiling and targeted therapies [Byers and Rudin, 2015]. Therefore, new methods for early detection of SCLC are necessary in order to address these shortcomings. Because our present study substantiates our previous findings that the robust CBMN biomarker assay is a sensitive tool for the identification of individuals at high risk of developing lung cancer, in general, we believe it may be further used to identify lung cancer subtypes such as SCLC through the addition of molecular cytogenetic techniques. Using such an approach may further elucidate the underlying molecular mechanisms associated with SCLC and foster the development of strategies for earlier SCLC detection.

\section{Acknowledgements}

This work has been partially funded by NIH through CA129050 and Cancer Center Support Grant P30CA016672.

\section{Statement of Ethics}

The study was approved by the Institutional Review Boards of the University of Texas MD Anderson Cancer Center and KelseySeybold Clinic. All study participants signed an informed consent prior to enrollment and were coded using a unique study ID throughout the study.

\section{Disclosure Statement}

The authors have no conflicts of interest to declare.

\section{References}

Argiris A, Murren JR: Staging and clinical prognostic factors for small-cell lung cancer. Cancer J 7:437-447 (2001).

Balsara BR, Testa JR: Chromosomal imbalances in human lung cancer. Oncogene 21:68776883 (2002).

Baykara O, Bakir B, Buyru N, Kaynak K, Dalay N: Amplification of chromosome 8 genes in lung cancer. J Cancer 6:270-275 (2015).

Bonassi S, Hagmar L, Stromberg U, Montagud $\mathrm{AH}$, Tinnerberg H, et al: Chromosomal aberrations in lymphocytes predict human cancer independently of exposure to carcinogens. European Study Group on Cytogenetic Biomarkers and Health. Cancer Res 60:16191625 (2000).

Bonassi S, Znaor A, Norppa H, Hagmar L: Chromosomal aberrations and risk of cancer in humans: an epidemiologic perspective. Cytogenet Genome Res 104:376-382 (2004).

Bonassi S, El-Zein R, Bolognesi C, Fenech M: Micronuclei frequency in peripheral blood lymphocytes and cancer risk: evidence from human studies. Mutagenesis 26:93-100 (2011).

Byers LA, Rudin CM: Small cell lung cancer: where do we go from here? Cancer 121:664672 (2015).

Cooper S, Spiro SG: Small cell lung cancer: treatment review. Respirology 11:241-248 (2006).

Crasta K, Ganem NJ, Dagher R, Lantermann AB, Ivanova EV, et al: DNA breaks and chromosome pulverization from errors in mitosis. Nature 482:53-58 (2012).

D’Amico D, Carbone D, Mitsudomi T, Nau M, Fedorko J, et al: High frequency of somatically acquired p53 mutations in small-cell lung cancer cell lines and tumors. Oncogene 7: 339-346 (1992).
Dave BJ, Hopwood VL, Hughes JI, Mellilo D, Jackson GL, Pathak S: Nonrandom chromosomal abnormalities in lymphocyte cultures of individuals with colorectal polyps and of asymptomatic relatives of patients with colorectal cancer or polyps. Cancer Epidemiol Biomarkers Prev 2:587-591 (1993).

Dave BJ, Hopwood VL, King TM, Jiang H, Spitz MR, Pathak S: Genetic susceptibility to lung cancer as determined by lymphocytic chromosome analysis. Cancer Epidemiol Biomarkers Prev 4:743-749 (1995).

Devesa SS, Bray F, Vizcaino AP, Parkin DM: International lung cancer trends by histologic type: male:female differences diminishing and adenocarcinoma rates rising. Int J Cancer 117:294-299 (2005)

Ding L, Getz G, Wheeler DA, Mardis ER, McLellan $\mathrm{MD}$, et al: Somatic mutations affect key pathways in lung adenocarcinoma. Nature 455:1069-1075 (2008).

El-Zein RA, Schabath MB, Etzel CJ, Lopez MS, Franklin JD, Spitz MR: Cytokinesis-blocked micronucleus assay as a novel biomarker for lung cancer risk. Cancer Res 66:6449-6456 (2006).

El-Zein RA, Fenech M, Lopez MS, Spitz MR, Etzel CJ: Cytokinesis-blocked micronucleus cytome assay biomarkers identify lung cancer cases amongst smokers. Cancer Epidemiol Biomarkers Prev 17:1111-1119 (2008).

El-Zein RA, Lopez MS, D’Amelio AM Jr, Liu M, Munden RF, et al: The cytokinesis-blocked micronucleus assay as a strong predictor of lung cancer: extension of a lung cancer risk prediction model. Cancer Epidemiol Biomarkers Prev 23:2462-2470 (2014).
Fenech $\mathrm{M}$ : The in vitro micronucleus technique. Mutat Res 455:81-95 (2000).

Fenech M: Biomarkers of genetic damage for cancer epidemiology. Toxicology 181-182:411416 (2002a).

Fenech M: Chromosomal biomarkers of genomic instability relevant to cancer. Drug Discov Today 7:1128-1137 (2002b).

Fenech M: Cytokinesis-block micronucleus cytome assay. Nat Protocol 2:1084-1104 (2007).

Fenech M, Morley AA: Measurement of micronuclei in lymphocytes. Mutat Res 147:29-36 (1985).

Fenech M, Chang WP, Kirsch-Volders M, Holland $\mathrm{N}$, Bonassi $\mathrm{S}$, et al: HUMN project: detailed description of the scoring criteria for the cytokinesis-block micronucleus assay using isolated human lymphocyte cultures. $\mathrm{Mu}$ tat Res 534:65-75 (2003)

Ferlay J, Shin HR, Bray F, Forman D, Mathers C, Parkin DM: Estimates of worldwide burden of cancer in 2008: GLOBOCAN 2008. Int J Cancer 127:2893-2917 (2010).

Franklin WF, Noguchi M, Gonzalez A: Molecular and cellular pathology of lung cancer, in Pass HI, Carbone DP, Johnson DH, Minna JD, Scagliotti GV, Turrisi AT (eds): Principles and Practice of Lung Cancer, ed 4, pp 287-324 (Lippincott Williams \& Wilkins, Philadelphia 2010).

Garnis C, Campbell J, Davies JJ, Macaulay C, Lam S, Lam WL: Involvement of multiple developmental genes on chromosome $1 \mathrm{p}$ in lung tumorigenesis. Hum Mol Genet 14:475-482 (2005).

Gjayee H, Dinney C, Pathak S: Do lymphocytes contain chromosomal lesions that are also stable markers in cancer cells? Inter J Oncology 11:681-684 (1997). 
Greene FL: Staging of colon and rectal cancer: from endoscopy to molecular markers. Surg Endosc 20:S475-478 (2006).

Haga Y, Hiroshima K, Iyoda A, Kohno H, Shibuya $\mathrm{K}$, et al: Frequency of loss of heterozygosity at 3 p, 9 p, 13 q, and 17 p is related to proliferative activity in smokers with stage I non-small cell lung cancer. Thorac Cardiovasc Surg 53: 114-117 (2005).

Hassan WA, Yoshida R, Kudoh S, Hasegawa K, Niimori-Kita K, Ito T: Notch1 controls cell invasion and metastasis in small cell lung carcinoma cell lines. Lung Cancer 86:304-310 (2014).

Hintzsche H, Hemmann U, Poth A, Utesch D, Lott J, et al: Fate of micronuclei and micronucleated cells. Mutat Res 771:85-98 (2017).

Hu Z, Wu C, Shi Y, Guo H, Zhao X, et al: A genome-wide association study identifies two new lung cancer susceptibility loci at 13q12.12 and 22q12.2 in Han Chinese. Nat Genet 43: 792-796 (2011).

Iwakawa R, Takenaka M, Kohno T, Shimada Y, Totoki Y, et al: Genome-wide identification of genes with amplification and/or fusion in small cell lung cancer. Genes Chromosomes Cancer 52:802-816 (2013).

Kim YH, Girard L, Giacomini CP, Wang P, Hernandez-Boussard T, et al: Combined microarray analysis of small cell lung cancer reveals altered apoptotic balance and distinct expression signatures of MYC family gene amplification. Oncogene 25:130-138 (2006).

Kim YH, Kwei KA, Girard L, Salari K, Kao J, et al: Genomic and functional analysis identifies $C R K L$ as an oncogene amplified in lung cancer. Oncogene 29:1421-1430 (2010).

Larsen JE, Minna JD: Molecular biology of lung cancer: clinical implications. Clin Chest Med 32:703-740 (2011).

Liou SH, Lung JC, Chen YH, Yang T, Hsieh LL, et al: Increased chromosome-type chromosome aberration frequencies as biomarkers of cancer risk in a blackfoot endemic area. Cancer Res 59:1481-1484 (1999).

Ma J, Gao M, Lu Y, Feng X, Zhang J, et al: Gain of $1 \mathrm{q} 25-32,12 \mathrm{q} 23-24.3$, and $17 \mathrm{q} 12-22$ facilitates tumorigenesis and progression of human squamous cell lung cancer. J Pathol 210: 205-213 (2006).

Masuda A, Takahashi T: Chromosome instability in human lung cancers: possible underlying mechanisms and potential consequences in the pathogenesis. Oncogene 21:6884-6897 (2002).

McHugh MK, Lopez MS, Ho CH, Spitz MR, Etzel CJ, El-Zein RA: Use of the cytokinesisblocked micronucleus assay to detect gender differences and genetic instability in a lung cancer case-control study. Cancer Epidemiol Biomarkers Prev 22:135-145 (2013).

Miller CW, Simon K, Aslo A, Kok K, Yokota J, et al: p53 mutations in human lung tumors. Cancer Res 52:1695-1698 (1992).

Nishikawa N, Toyota M, Suzuki H, Honma T, Fujikane T, et al: Gene amplification and overexpression of PRDM14 in breast cancers. Cancer Res 67:9649-9657 (2007).

Norppa H, Bonassi S, Hansteen IL, Hagmar L, Strömberg U, et al: Chromosomal aberrations and SCEs as biomarkers of cancer risk. Mutat Res 600:37-45 (2006).

Pathak S, Hopwood VL, Hortobagyi GN, Jackson GL, Hughes JI, Melillo D: Chromosome anomalies in human breast cancer: evidence for specific involvement of $1 \mathrm{q}$ region in lymphocyte cultures. Anticancer Res 11:10551060 (1991).

Pei J, Balsara BR, Li W, Litwin S, Gabrielson E, et al: Genomic imbalances in human lung adenocarcinomas and squamous cell carcinomas. Genes Chromosomes Cancer 31:282-287 (2001).

Petersen I, Petersen S, Bockmühl U, Schwendel A, Wolf G, Dietel M: Comparative genomic hybridization of bronchial carcinomas and their metastases (in German). Verh Dtsch Ges Pathol 81:297-305 (1997).

Qian J, Massion PP: Role of chromosome 3q amplification in lung cancer. J Thorac Oncol 3: 212-215 (2008).

Rami-Porta R, Ball D, Crowley J, Giroux DJ, Jett J, et al: The IASLC Lung Cancer Staging Project: proposals for the revision of the T descriptors in the forthcoming (seventh) edition of the TNM classification for lung cancer. J Thorac Oncol 2:593-602 (2007).

Reynisdottir I, Arason A, Einarsdottir BO, Gunnarsson $\mathrm{H}$, Staaf J, et al: High expression of ZNF703 independent of amplification indicates worse prognosis in patients with luminal B breast cancer. Cancer Med 2:437-446 (2013).

Ruark E, Seal S, McDonald H, Zhang F, Elliot A, et al: Identification of nine new susceptibility loci for testicular cancer, including variants near DAZL and PRDM14. Nat Genet 45:686689 (2013).

Saldivar JC, Shibata H, Huebner K: Pathology and biology associated with the fragile FHIT gene and gene product. J Cell Biochem 109:858865 (2010).

Schwartz AG, Wenzlaff AS, Bock CH, Ruterbusch JJ, Chen W, et al: Admixture mapping of lung cancer in 1812 African-Americans. Carcinogenesis 32:312-317 (2011).
Slorach EM, Chou J, Werb Z: Zeppo1 is a novel metastasis promoter that represses E-cadherin expression and regulates p120-catenin isoform expression and localization. Genes Dev 25:471-484 (2011).

Smerhovsky Z, Landa K, Rössner P, Brabec M, Zudova Z, et al: Risk of cancer in an occupationally exposed cohort with increased level of chromosomal aberrations. Environ Health Perspect 109:41-45 (2001).

Sos ML, Dietlein F, Peifer M, Schöttle J, BalkeWant $\mathrm{H}$, et al: A framework for identification of actionable cancer genome dependencies in small cell lung cancer. Proc Natl Acad Sci USA 109:17034-17039 (2012).

Stephens PJ, Greenman CD, Fu B, Yang F, Bignell $\mathrm{GR}$, et al: Massive genomic rearrangement acquired in a single catastrophic event during cancer development. Cell 144:27-40 (2011).

Stewenius Y, Gorunova L, Jonson T, Larsson N, Höglund M, et al: Structural and numerical chromosome changes in colon cancer develop through telomere-mediated anaphase bridges, not through mitotic multipolarity. Proc Natl Acad Sci USA 102:5541-5546 (2005).

Tucker JD, Preston RJ: Chromosome aberrations, micronuclei, aneuploidy, sister chromatid exchanges, and cancer risk assessment. Mutat Res 365:147-159 (1996).

Umegaki K, Fenech M: Cytokinesis-block micronucleus assay in WIL2-NS cells: a sensitive system to detect chromosomal damage induced by reactive oxygen species and activated human neutrophils. Mutagenesis 15:261269 (2000).

van Meerbeeck JP, Fennell DA, De Ruysscher DK: Small-cell lung cancer. Lancet 378:1741-1755 (2011).

Voortman J, Lee JH, Killian JK, Suuriniemi M, Wang Y, et al: Array comparative genomic hybridization-based characterization of genetic alterations in pulmonary neuroendocrine tumors. Proc Natl Acad Sci USA 107: 13040-13045 (2010).

Wali A: FHIT: doubts are clear now. Scientific World Journal 10:1142-1151 (2010).

Wistuba II, Gazdar AF, Minna JD: Molecular genetics of small cell lung carcinoma. Semin Oncol 28:3-13 (2001).

Worden FP, Kalemkerian GP: Therapeutic advances in small cell lung cancer. Expert Opin Investig Drugs 9:565-579 (2000).

Zhao X, Weir BA, LaFramboise T, Lin M, Beroukhim R, et al: Homozygous deletions and chromosome amplifications in human lung carcinomas revealed by single nucleotide polymorphism array analysis. Cancer Res 65 : 5561-5570 (2005).
Biological Markers for Lung Cancer Subtypes
Cytogenet Genome Res 2017;152:122-131 DOI: $10.1159 / 000479809$ 